\title{
Sympathochromaffin System Activity in the Elderly
}

Oscar A. Linares, $M D$, and Jeffrey B. Halter, $M D$

$\Gamma$ he sympathochromaffin system is composed of the sympathetic nervous system (SNS) and the adrenal medullae. ${ }^{1}$ This system plays a key role to mediate internal adaptation to changes in the external environment, thus maintaining essential body functions such as blood pressure, body temperature, and fuel metabolism within a narrow range. There is evidence of impaired regulation of blood pressure, body temperature, and carbohydrate metabolism in the elderly. ${ }^{2-5}$ Thus, there has been considerable interest in understanding the effect of aging on function of the sympathochromaffin system. The purpose of this paper is to review and discuss recent observations regarding the study of sympathochromaffin system activity in human aging, as assessed by measurement of plasma catecholamine levels and calculation of kinetic indices of catecholamine metabolism.

\section{PHYSIOLOGY OF THE SYMPATHOCHROMAFFIN SYSTEM}

Norepinephrine (NE) is the major neurohumoral messenger mediating SNS effects, while epinephrine (E) is the major catecholamine released by the adrenal medullae $^{6}$ (Figure 1). Specific sensitive assays have made it possible to measure plasma NE and E levels under a variety of conditions. ${ }^{7-10}$ These studies have provided useful information about sympathochromaffin system activity in humans. ${ }^{11}$ However, the level of catecholamine in plasma is the result of at least two dynamic processes: appearance into, and clearance from, the circulation. ${ }^{12}$

Norepinephrine in the circulation is derived mainly

From the Division of Geriatric Medicine, Department of Internal Medicine, University of Michigan Medical School, and Veterans Administration Medical Center, Ann Arbor, Michigan.

Address correspondence and reprint requests to Dr. Oscar A. Linares, University of Michigan Medical Center, Division of Geriatric Medicine, 1010 Wall Street, Ann Arbor, MI 48109-0010. from "spillover" of NE released from postganglionic sympathetic nerve terminals. ${ }^{13}$ Following its release into the neuroeffector junction of sympathetic nerve synapses, most of the NE is removed from that site by reuptake (uptake ${ }_{1}$; neuronal removal) into the presynaptic nerve terminals. Some of the released NE escapes this process and is removed by uptake ${ }_{2}$ (nonneuronal removal). Finally, a small fraction of NE in the neuroeffector junction spills over into the circulation (Figure 1). Plasma NE is, therefore, an indirect measure of SNS outflow. In contrast, the adrenal gland is the major source of circulating E. Epinephrine is released directly into the circulation from the adrenal medullae and transported via the circulation to its target cells (Figure 1). Uptake ${ }_{1}$ is more important for inactivation of $\mathrm{NE}$ than $\mathrm{E}$, while uptake $\mathrm{e}_{2}$ appears to be the major mechanism for inactivation of circulating E. ${ }^{14,15}$ The plasma $E$ level provides a direct measure of chromaffin tissue activity, including the adrenal medullae, under normal physiologic conditions. ${ }^{1}$

\section{PLASMA CATECHOLAMINES IN THE ELDERLY}

Plasma Norepinephrine Levels Investigations from several laboratories have confirmed that plasma NE levels at rest are significantly higher in older individuals. ${ }^{16-18}$ Under appropriate conditions, increases in plasma NE levels appear to provide a sensitive and useful index of sympathetic neuronal function. ${ }^{19}$ Thus, the higher plasma NE levels in older individuals suggest that SNS activity is increased in the elderly. The correlation observed between plasma NE and direct recording of muscle sympathetic nerve activity in humans ${ }^{20}$ further supports this hypothesis.

In addition to the age-related increase of plasma NE in the supine resting state, as shown in Figure 2, plasma NE levels are elevated in the elderly throughout the 24-hour diurnal rhythm. ${ }^{21}$ Several physiologic maneuvers elicit a heightened plasma NE response 


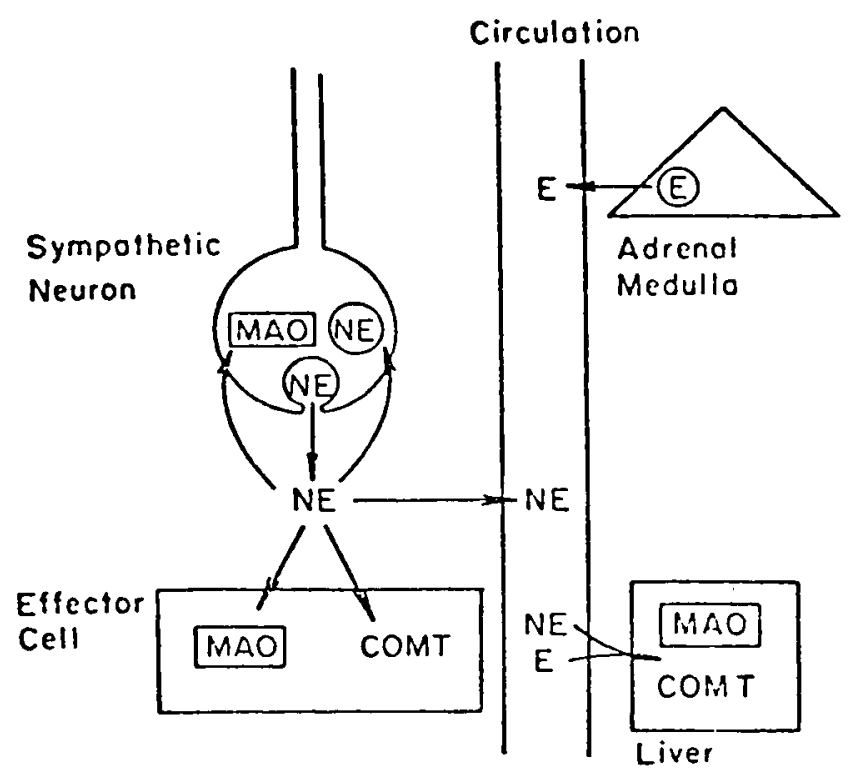

FIGURE 1. Sources of circulating catecholamines. Norepinephrine $(N E)$ is released from postganglionic sympathetic neurons into the synaptic cleft from where the majority is taken back up into the neuron and either stored in granules or metabolized by monoamine oxidase (MAO). Some of the remaining NE is enzymatically degraded by $\mathrm{MAO}$ and catechol-O-methyltransferase (COMT) locally and only a small fraction spills over into the circulation. Epinephrine is released from the adrenal medullae directly into the circulation and the majority is removed from the circulation.

in humans. ${ }^{10}$ There is evidence that plasma NE responses are significantly higher in older individuals during mental stress, ${ }^{22}$ upright posture, ${ }^{23}$ isometric exercise, ${ }^{24}$ glucose administration, ${ }^{23}$ and sodium restriction. ${ }^{25}$

Plasma Epinephrine Levels Despite the consistent findings of increased plasma NE with advancing age

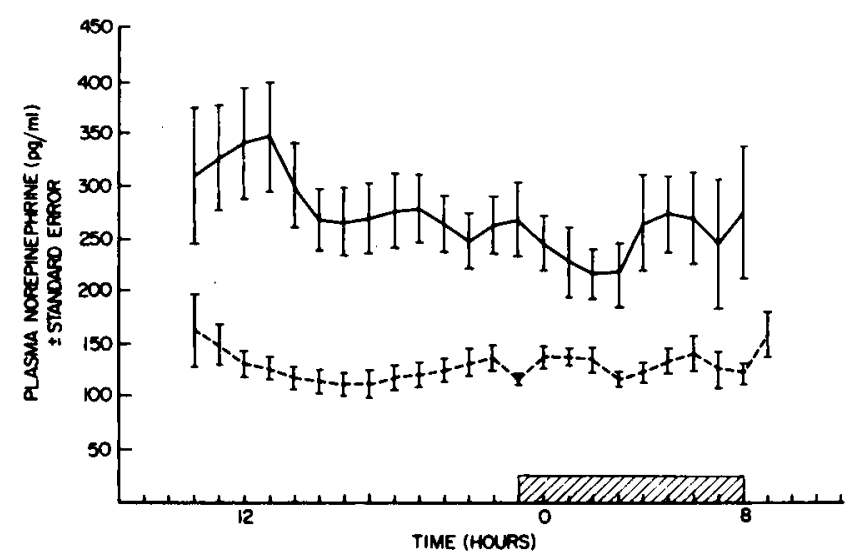

FIGURE 2. Plasma norepinephrine (NE) concentrations over a normal undisturbed 24-hr period in 8 old and 10 young men. Plasma NE is higher in the old throughout the day, including the time during sleep (hatched box). ${ }^{21}-\ldots=$ aged normals $(N=$ $8) ;---=$ young normals $(N=10)$. both at rest and during SNS activation, no age differences have been reported for plasma E. Plasma E levels are similar in healthy elderly and young subjects throughout the day. ${ }^{21,22}$ In addition, the plasma E response to a mental stress test is identical in elderly and young participants. ${ }^{22}$

\section{CATECHOLAMINE KINETICS IN THE ASSESSMENT OF SYMPATHOCHROMAFFIN SYSTEM ACTIVITY}

Infusion of Nonradiolabelled Catecholamines In this method NE or E is infused at a constant rate until a plateau plasma level is achieved. ${ }^{26}$ Clearance $(\mathrm{L} / \mathrm{min})$ is calculated using the following equation:

$$
\begin{gathered}
\text { Clearance } \\
=\text { infusion rate/plateau plasma level } \\
- \text { basal level. }
\end{gathered}
$$

Calculation of catecholamine clearance rate allows estimation of the rate of catecholamine appearance into the circulation $\left(\mathrm{CA}_{\mathrm{AR}}\right)$ using the following equation:

$$
\begin{aligned}
\mathrm{CA}_{\mathrm{AR}}=\mathrm{CA} \text { clearance } & \\
& \times \text { basal CA concentration. }
\end{aligned}
$$

This method is based on three major assumptions. First, it assumes that steady state conditions have been achieved. Second, the infusion of exogenous catecholamine must not influence the appearance or clearance of endogenous catecholamine. Third, the method assumes that the kinetics of distribution and metabolism of the catecholamine systems can be represented by a single-compartment model, ie, all de novo sources of catecholamine enter into, and all irreversible losses leave from, the accessible (sampled) compartment.

This technique has been used in only two studies addressing NE kinetics with aging. Young et al. ${ }^{23}$ found no significant change in NE clearance rate in five elderly participants compared to five young controls. Rubin et al. ${ }^{27}$ studied eight young and eight elderly participants and found that NE clearance rate was unchanged in the elderly whereas NE appearance rate was significantly increased in this group both in the supine position and during upright posture.

Infusion of Radiolabelled Catecholamines The major assumptions underlying this approach are the same as those for the nonradiolabelled catecholamine infusion technique. ${ }^{26}$ However, because tracer doses of catecholamines are used, it is very likely that this method does not disturb endogenous NE management. The rates employed during infusion of radiolabelled NE are 25 to 50 times < a NE infusion rate previously shown to have no effect on blood pressure and other metabolic parameters, ${ }^{28}$ and they are 16 times $<$ a NE infusion rate previously shown to cause 
an increment of $3.0 \mathrm{pg} / \mathrm{mL}$ in plasma NE levels. ${ }^{29}$ The radiolabelled NE infusion approach allows calculation of $\mathrm{NE}$ appearance rate $\left(\mathrm{NE}_{\mathrm{AR}}\right)$ into, and $\mathrm{NE}$ clearance $\left(N E_{C L}\right)$ rate from, the circulation based on the following mathematical relationships:

$$
\mathrm{NE}_{\mathrm{AR}}=\frac{{ }^{3} \mathrm{H}-\mathrm{NE} \text { infusion rate }(\mathrm{dpm} / \mathrm{mL})}{\text { Specific activity of Plasma NE }(\mathrm{dpm} / \mathrm{pg})}
$$

and

$$
\mathrm{NE}_{\mathrm{CL}}=\frac{{ }^{3} \mathrm{H}-\mathrm{NE} \text { infusion rate }(\mathrm{dpm} / \mathrm{mL})}{\text { Steady state plasma }\left({ }^{3} \mathrm{H}-\mathrm{NE}[\mathrm{dpm} / \mathrm{mL}]\right)}
$$

Using this approach, Esler et al. ${ }^{30}$ studied 34 healthy people ages 20 to 69 years of age and found a significant $30 \%$ reduction in $\mathrm{NE}_{\mathrm{CL}}$ and an nonsignificant $14 \%$ increase in $\mathrm{NE}_{\mathrm{AR}}$ in the elderly. In contrast, Hoeldtke and Cilmi ${ }^{31}$ studied 13 elderly and 14 young participants and found that $\mathrm{NE}_{\mathrm{AR}}$ is increased with advancing age while $N E_{C L}$ is not significantly reduced. In addition, they used a complex urinary catecholamine metabolite excretion technique ${ }^{32}$ combined with the ${ }^{3} \mathrm{H}-\mathrm{NE}$ infusion method, correcting for estimated contributions due to brain and adrenal catecholamine excretion, to estimate total NE secretion by peripheral sympathetic nerves. Using this technique they reported that peripheral NE secretion is not increased in the elderly.

In the largest study to date ( 25 young and 18 elderly subjects) addressing the question of whether increased plasma NE levels in the elderly are due to increased $\mathrm{NE}_{\mathrm{AR}}$ or decreased $\mathrm{NE}_{\mathrm{CL}}$, or a combination of both factors, we found both increased $\mathrm{NE}_{\mathrm{AR}}$ and decreased $\mathrm{NE}_{\mathrm{CL}}$ in the elderly. ${ }^{33}$ These findings are illustrated in Figures 3 and 4. Because either the increased $\mathrm{NE}_{\mathrm{AR}}$ or decreased $\mathrm{NE}_{\mathrm{CL}}$ could contribute to the age-related elevation of plasma NE, forward-stepwise multiple linear regression analysis and partial correlations were used to determine which of the two was the more important determinant. The linear model, $\mathrm{NE}=197+717\left(\mathrm{NE}_{\mathrm{AR}}\right)-129\left(\mathrm{NE}_{\mathrm{CL}}\right)$, revealed that $\mathrm{NE}_{\mathrm{AR}}$ and $\mathrm{NE}_{\mathrm{CL}}$ explained $80 \%$ of the variance in plasma $\mathrm{NE}$ levels. Partial correlations showed that $\mathrm{NE}_{\mathrm{AR}}$ alone accounted for $57 \%$ and $\mathrm{NE}_{\mathrm{CL}}$ contributed $14 \%$ indicating that $\mathrm{NE}_{\mathrm{AR}}$ is the more important determinant.

A subsequent study explored the possibility that diminished $\alpha-2$ adrenergic inhibition of SNS outflow might account for the elevation of plasma NE and plasma NE appearance rate observed in older individuals. ${ }^{34}$ If the increased plasma NE appearance rate in the elderly is due to a primary defect or loss of inhibitory $\alpha-2$ receptors, this should be associated with an attenuated response to the $\alpha-2$ adrenergic receptor agonist clonidine in the older subjects. However, clo-

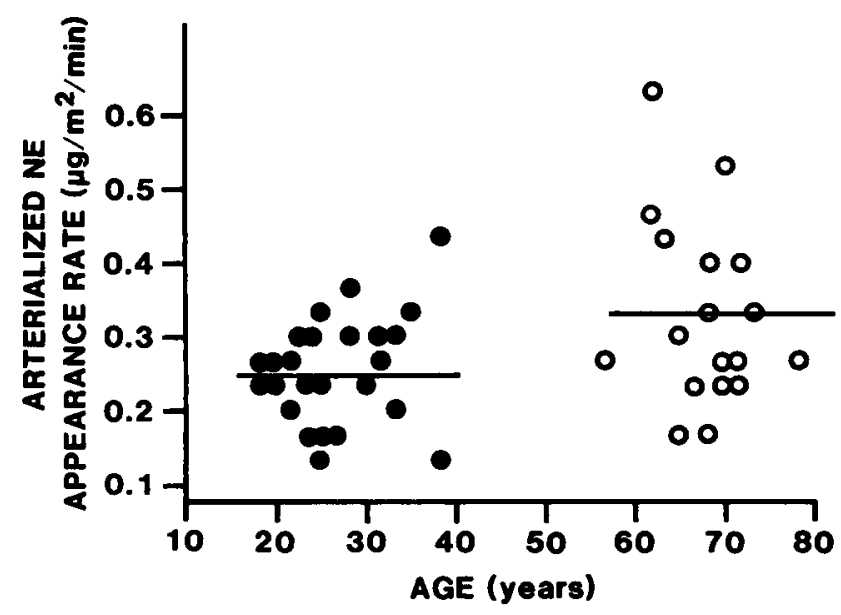

FIGURE 3. Arterialized plasma norepinephrine (NE) appearance rate during ${ }^{3} \mathrm{H}=\mathrm{NE}$ infusion for young (O) and old (O) adults. The values of the old averaged $30 \%$ higher than those of the young. ${ }^{33} \mathrm{P}<0.016$.

nidine was found to suppress plasma NE and NE appearance rate equally in young and older subjects, which suggests that the $\alpha-2$ adrenergic mechanisms regulating SNS activity are functionally intact in older individuals.

Epinephrine Kine'ics The basic analytic theory for calculation of clearance and appearance rates (see above) applies equally to the study of $E$ kinetics. The nonradiolabeled $\mathrm{E}$ infusion technique has been used to compare the pattern of change in plasma $\mathrm{E}$ in young and elderly subjects. Wilkie et al. ${ }^{35}$ found that lower plasma $E$ levels were achieved by $E$ infusion in the elderly participants. As a result, values calculated for E clearance were significantly higher in old than young

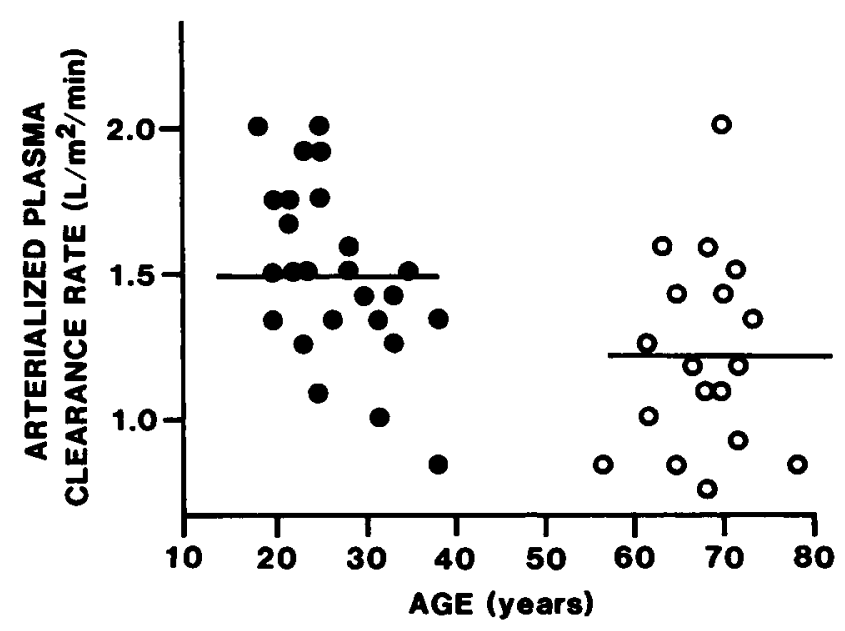

FIGURE 4. Arterialized plasma norepinephrine (NE) clearance rate during ${ }^{3} \mathrm{H}=N E$ infusion for young (O) and old $(\mathrm{O})$ adults. The values of the old averaged $14 \%$ lower than those of the young. ${ }^{33}$ $\mathbf{P}<0.006$. 
subjects. More recently, we have reported the results of preliminary studies of $\mathrm{E}$ kinetics using radiolabelled E. ${ }^{36}$ Basal $E$ appearance rate was not significantly different in old and young, but $E$ clearance was increased in the elderly, confirming the earlier findings with unlabelled $E$ infusion. The findings suggesting increased $E$ clearance in the elderly appear paradoxical, since NE clearance is diminished in the elderly. NE and $E$ are removed by both uptake $e_{1}$ and uptake $e_{2}$ mechanisms. Furthermore, in young subjects the clearance rate of NE and $\mathrm{E}$ are virtually identical. ${ }^{37}$ These findings imply a differential effect of age on a catecholamine removal mechanism that has a greater affinity for NE than for $E$.

\section{PHYSIOLOGICAL IMPLICATIONS}

What is the physiological, pathophysiological, and clinical significance of altered sympathochromaffin system activity with aging? Arterial blood pressure has been observed to increase as a function of age in humans, both in cross-sectional and longitudinal studies. ${ }^{2}$ Increased SNS activity with resulting cardiac stimulation and vasoconstriction is a potential mechanism for such age-related increases of blood pressure, although blood pressure regulation is a complex process involving a number of neuroendocrine systems in addition to the SNS. ${ }^{38}$ Although supine blood pressure tends to increase with age, orthostatic hypotension has also been reported to be a problem among older people. ${ }^{39,40}$ The paradoxical findings of both increased blood pressure and orthostatic hypotension in the elderly raise the possibility of an agerelated impairment of the baroreceptor mechanism which controls SNS input to the cardiovascular system. Such a possible age-related impairment of regulation of SNS control of arterial blood pressure would be of particular importance in the many elderly individuals who have medical problems which involve use of therapeutic regimens which can affect SNS activity (eg, diuretics, adrenergic blocking agents, antidepressant drugs, tranquilizers).

Pfeifer et al. ${ }^{18}$ found decreased respiratory heart rate variability in the elderly, providing evidence for decreased parasympathetic nervous system (PNS) input to the heart. Because plasma NE levels were higher in the elderly, increased SNS input to the heart was postulated. One potential mechanism for such a link of increased SNS and decreased PNS activity is via the baroreceptor signaling mechanism, since a decline of arterial blood pressure normally results in simultaneous baroreceptor mediated increases of SNS and decreases of PNS activity. Since blood pressure in these elderly subjects was higher, not lower than in young people, a defective baroreceptor signaling mechanism and/or defective central nervous system processing of baroreceptor signals was hypothesized.

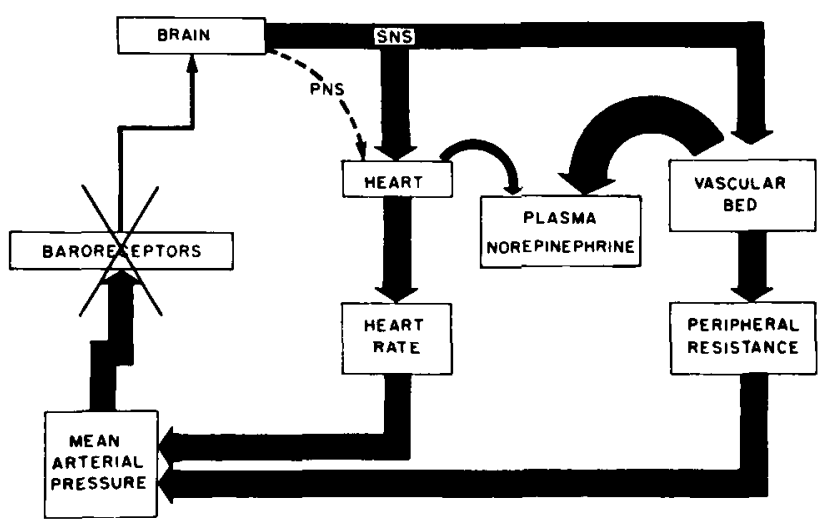

FIGURE 5. Model of compensated autonomic nervous system regulation of the cardiovascular system in response to baroreceptor dysfunction. In this hypothetical model, an impairment of baroreceptor sensitivity, afferent neural transmission, or central processing of the brain initially results in central perception of low blood pressure. To compensate, cardiac and vascular sympathetic nervous system (SNS) activity increases and cardiac parasympathetic nervous system (PNS) activity decreases. These responses result in a compensatory increase in blood pressure, which stimulates the impaired baroreceptor system sufficiently so that the central nervous system perceives that the blood pressure has normalized. ${ }^{18}$

As illustrated in Figure 5, such a defect could explain the findings of an age-related increase of blood pressure associated with increased SNS activity and decreased PNS activity. Similarly, Rowe and Troen ${ }^{17}$ and Christensen ${ }^{41}$ have suggested that the increases of plasma NE levels with aging may be due in part to impaired baroreceptor sensitivity.

Alternatively, the high NE levels in the elderly could represent a physiologic response to decreased cellular responsiveness to catecholamines. Evidence for an age-related impairment of tissue responsiveness to catecholamines, particularly to $\beta$-adrenergic receptor stimulation, has recently been reviewed. ${ }^{42}$ However, an age-related increase of plasma NE levels to compensate for impaired adrenergic mechanisms cannot explain the observed elevated arterial blood pressure in the elderly. Since increased exposure to catecholamines can result in desensitization of adrenergic receptor function, ${ }^{43}$ it is perhaps more likely that the age-related change in adrenergic receptors is secondary to the increase of NE levels.

If such a hypothesized baroreceptor signaling mechanism defect in the elderly exists, the increase of SNS activity may be specific for the cardiovascular system. For example, Pfeifer et al. ${ }^{18}$ also found evidence that SNS input to the iris is not increased in the elderly. In addition, adrenal medullary activity as measured by both plasma $E$ levels and nonradiolabelled and radiolabelled $E$ kinetic indices, is not increased in the elderly. ${ }^{35-37}$ These organs are not heav- 
ily influenced by alterations of baroreceptor function. Thus it is possible that an impaired baroreceptor mechanism leads to a selective compensatory increase of cardiovascular SNS activity in the elderly.

\section{SUMMARY AND FUTURE DIRECTIONS}

Current findings indicate that aging in humans is associated with increased circulating levels of NE, primarily due to increased spillover of NE into the circulation. Current work has focused on plasma NE levels and the kinetics of circulating NE. However, the concept of a single compartment for NE is not in accord with the known physiology of NE metabolism which includes NE removal from the synaptic cleft by neuronal and nonneuronal mechanisms, and spillover of NE only secondarily from the synaptic cleft into the circulation. Thus, of more physiologic importance, are the kinetics of NE release and removal from the extravascular sites at which NE is released. Recent work indicates that a physiologically based two-compartment differential equation model can reproducibly predict the kinetics of distribution and metabolism of both NE and E. ${ }^{44,45}$ The use of the powerful tools of computer assisted mathematical modeling ${ }^{46,47}$ may allow quantitative estimation of catecholamine kinetics in the inaccessible sites of distribution and metabolism of the catecholamines, and provide further insight into the regulation of sympathochromaffin system function with aging.

\section{ACKNOWLEDGMENTS}

This work was supported by the Medical Research Service of the Veterans Administration and by NIH grant AG00305.

\section{REFERENCES}

1. Shah SD, Tse TF, Clutter WE, et al: The human sympathochromaffin system. Am J Physiol 247:E380, 1984

2. Kohn RR: Heart and cardiovascular system, in Finch CE, Hayflick L (eds): Handbook of the Biology of Aging. Van Nostrand Reinhold Co., p 291-297, 1977

3. Collins KF, Dore C, Eaton-Smith AN, et al: Accidental hypothermia and impaired temperature homeostasis in the elderly. Br Med J 1:353, 1977

4. Davidson MB: The effect of aging on carbohydrate metabolism: A review of the English literature and a practical approach to the diagnosis of diabetes mellitus in the elderly. Metabolism 28:668, 1979

5. Reaven GM, Reaven EP: Age, glucose intolerance, and noninsulin-dependent diabetes mellitus. J Am Geriatr Soc 33:286, 1985

6. Axelrod J, Weinshilboum R: Catecholamines. N Engl J Med 287:237, 1972

7. Passon PG, Peuler JD: A simplified radiometric assay for plasma norepinephrine and epinephrine. Anal Biochem 51:618, 1973

8. Cryer PE, Santiago JV, Shah S: Measurement of nor- epinephrine and epinephrine in small volumes of human plasma by a single isotope enzymatic derivative method: Response to upright posture. J Clin Endocrinol Metab 39:1025, 1974

9. Evans MI, Halter JB, Porte D: Comparison of doubleand single-isotope enzymatic derivative methods for measuring catecholamines in human plasma. Clin Chem 24:567, 1978

10. Robertson D, Johnson GA, Robertson RM, et al: Comparative assessment of stimuli that release neuronal and adrenomedullary catecholamines in man. Circulation 59:637, 1979

11. Cryer PE: Physiology and pathophysiology of the human sympathoadrenal neuroendocrine system. $N$ Engl J Med 303:436, 1980

12. Esler $M$, Leonard $P, O^{\prime}$ Dea $K$, et al: Biochemical quantification of sympathetic nervous activity in humans using radiotracer methodology: Fallability of plasma noradrenaline measurements. J Cardiovasc Pharmacol 4:S152, 1982

13. Kopin IJ, Lake CR, Ziegler MG: Plasma levels of norepinephrine. Ann Intern Med 88:671, 1978

14. Axelrod J: Noradrenaline: Fate and control of its biosynthesis. Science 173:598, 1971

15. LaBrosse EH, Axelrod J, Kety SS: O-methylation, the principal route of metabolism of epinephrine in man. Science 128:593, 1958

16. Ziegler MG, Lake CR, Kopin IJ: Plasma noradrenaline increases with age. Nature 261:333, 1976

17. Rowe JR, Troen BR: Sympathetic nervous system and aging in man. Endocr Rev 1:167, 1980

18. Pfeifer MA, Weinberg CR, Cook D, et al: Differential changes of autonomic nervous system function with age in man. Am J Med 75:249, 1983

19. Lake CR, Chernow B, Feuerstein G, et al: The sympathetic nervous system in man: Its evaluation and the measurement of plasma norepinephrine, in Ziegler MG, Lake CR (eds): Norepinephrine. Williams and Wilkins, Baltimore, pp 1-26, 1984

20. Wallin BG, Sundlöf G, Erikson BM, et al: Plasma noradrenaline correlates to sympathetic muscle nerve activity in normotensive man. Acta Physiol Scand III:69, 1981

21. Prinz PN, Halter JB, Benedetti C, et al: Circadian variation in plasma catecholamines in young and old men: Relation to eye movement and slow wave sleep. J Clin Endocrinol Metab 48:300, 1979

22. Barnes RF, Raskind M, Gumbrecht $G$, et al: The effects of age on the plasma catecholamine response to mental stress in man. J Clin Endocrinol Metab 54:64, 1982

23. Young JB, Rowe JW, Pallotta J, et al: Enhanced plasma norepinephrine response to upright posture and oral glucose administration in elderly subjects. Metabolism 29:532, 1980

24. Palmer GJ, Ziegler MG, Lake CR: Response of norepinephrine and blood pressure to stress increases with age. J Gerontol 33:482, 1978

25. Fiorica V: Plasma norepinephrine levels of elderly men on controlled sodium intake diet. J Am Geriatr Soc 32: 576,1984 
26. Halter JB, Best JD, Linares OA: Measurement of catecholamine kinetics in vivo, 'in Christensen NJ, Henricksen O, Lassen NA (eds): Adrenergic Physiology and Pathophysiology. New York, Raven Press, pp 38-51, 1986

27. Rubin $X$ et al: Noradrenaline release and clearance in relation to age and blood pressure in man. Eur J Clin Invest 12:121, 1982

28. Silverberg $A B$, Shah $S D$, Hammond MW, et al: Norepinephrine: Hormone and neurotransmitter in man. Am J Physiol 234:E252, 1978

29. Goldstein DS, Zimlichman R, Stull R, et al: Measurement of regional neuronal removal of norepinephrine in man. J Clin Invest 76:15, 1985

30. Esler M, Skews H, Leonard P, et al: Age-dependence of norepinephrine kinetics in normal subjects. Clin Sci $60: 217,1981$

31. Hoeldtke RD, Cilmi KM: Effects of aging on catecholamine metabolism. J Clin Endocrinol Metab 60:479, 1985

32. Hoeldtke RD, Cilmi KM, Reichard GA, et al: Assessment of norepinephrine secretion and production. J Lab Clin Med 101:772, 1983

33. Veith RC, Featherstone JA, Linares OA, et al: Age differences in plasma norepinephrine kinetics in humans. J Gerontol 41:319, 1986

34. Featherstone JA, Veith RC, Halter JB. Age and alpha2 adrenergic regulation of plasma norepinephrine kinetics in humans. J Gerontol (in press)

35. Wilkie FL, Halter JB, Prinz PN, et al: Age-related changes in venous catecholamines basally and during epinephrine infusion in man. J Gerontol 40:133, 1985

36. Hill TJ, Morrow LA, Sanfield JA, et al: Effect of age on epinephrine kinetics in humans. Clin Res 34:1000A, 1986
37. Morrow LA, Hill T], Linares OA, et al: Differences in clearance mechanisms for epinephrine and norepinephrine in humans unmasked by differential effects of aging. Clin Res 34:950A, 1986

38. Guyton AC: Circulatory Physiology III: Arterial Pressure and Hypertension. Philadelphia, W.B. Saunders, 1980

39. Johnson RH, Smith AC, Spalding JMK, et al: Effect of posture on blood-pressure in elderly patients. Lancet i:731, 1965

40. Caird FI, Andrews GR, Kennedy RD: Effect of posture on blood pressure in the elderly. Br Heart J 35:527, 1973

41. Christensen NJ: Sympathetic nervous activity and age. Eur J Clin Invest 12:91, 1982

42. Heinsimer JA, Lefkowitz RJ: The impact of aging on adrenergic receptors: Clinical and biochemical aspects. J Am Geriatr Soc 33:184, 1985

43. Davies AO, Lefkowitz RJ: Regulation of adrenergic receptors, in RJ Lefkowitz (ed): Receptors and Recognition. Series B. Volume 13. Receptor Regulation, Chapman and Hall, London, pp 83-122, 1981

44. Linares OA, Zech LA, Jacquez JA, et al: Norepinephrine metabolism in humans: A kinetic analysis and model. (Submitted for publication).

45. Sanfield JA, Rosen SG, Linares OA, et al: Compartmental analysis: A new approach to epinephrine kinetics in humans. Clin Res 33:827 A, 1985

46. Berman $\mathrm{M}$, Shahn $\mathrm{E}$, Weiss MF: The routine fitting of kinetic data to models: A mathematical formalism for digital computers. Biophys J 2:275, 1962

47. Riggs DS: The Mathematical Approach to Physiological Problems. Baltimore, Williams and Wilkins, 1963 